\title{
ОЦЕНКА РЕАКТОГЕННОСТИ,
}

БЕЗОПАСНОСТИ И ИММУНОГЕННОСТИ

ПОЛИСАХАРИДНОЙ ПНЕВМОКОККОВОЙ

ВАКЦИНЫ ПРИ ИММУНИЗАЦИИ

МЕДИЦИНСКИХ РАБОТНИКОВ

\author{
И.В. Фельдблюм ${ }^{1}$, С.О. Голоднова ${ }^{1}$, В.В. Семериков ${ }^{2}$, \\ В.В. Николенко ${ }^{1}$, Н.А. Метелкина ${ }^{2}$ \\ ${ }^{1}$ ГОУ ВПО Пермская государственная медицинская академия им. ак. Е.А. Вагнера Росздрава \\ ${ }^{2}$ Управление здравоохранения г. Перми
}

Резюме. В статье представлены результаты проспективного рандомизированного наблюдения за медицинскими работниками, иммунизированными полисахаридной пневмококковой вакциной «Пневмо 23», с целью оценки ее реактогенности, безопасности и иммуногенности. Вакцина характеризовалась высоким профилем безопасности (отсутствовали клинические проявления аллергических заболеваний, изменения лабораторных показателей крови и мочи) и достаточной иммуногенностью.

Ключевые слова: вакцина «Пневмо 23», реактогенность, безопасность, иммуногенность.

\section{THE EVALUATION OF REACTOGENICITY, SAFETY AND IMMUNOGENICITY OF THE POLYSACCHARIDE PNEUMOCOCCAL VACCINE DURING THE IMMUNIZATION OF HEALTH CARE WORKERS}

Feldblum I.V., Golodnova S.O., Semerikov V.V., Nikolenko V.V., Metelkina N.A.

Abstract. The article presents results of a prospective randomized study of reactogenicity, safety and immunogenicity of the polysaccharide pneumococcal vaccine "Pneumo 23" in the group of medical workers. The vaccine was characterized by the high profile of safety (absence of clinical symptoms of allergy, changes in blood and urine), low reactogenicity and sufficient immunogenicity. (Infekc. immun., 2011, vol. 1, $N$ 3, p. 275-278)

Key words: vaccine "Pneumo 23", reactogenicity, safety, immunogenicity.

\section{Введение}

Пневмококковая инфекция, вызванная Streptococcus pneumoniae (пневмококком), является одной из актуальных проблем современной медицины, так как в последние годы заболеваемость этой нозологией в мире сохраняется на высоком уровне - 15-24 на 100000 населения $[8,9]$. По данным работ отечественных и зарубежных авторов, пневмококки - наиболее частая причина возникновения внебольничных пневмоний (30-50\% от этиологически расшифрованных случаев), сепсиса и менингита $(7,1-$ $32,2 \%$ среди всех гнойных менингитов) $[3,5,7]$.
Согласно данным Минздравсоцразвития в России ежегодно регистрируется свыше 400 тыс. случаев внебольничных пневмоний, а умирает от нее более 40 тыс. человек. Вместе с тем, по мнению ведущих российских экспертов-пульмонологов, официальные цифры статистики $(0,41 \%$ от общей популяции, 2003) не отражают истинной распространенности внебольничной пневмонии в России, которая, согласно расчетам, достигает 1,4-1,5\% от общей популяции, или более 1,5 млн человек ежегодно [5].

Известно, что по сравнению с другими профессиональными группами медицинские ра- поступила в редакцию 08.06.11 принята к печати 14.06.11

(с) Фельдблюм И.В. и соавт., 2011
Адрес для переписки:

Фельдблюм Ирина Викторовна, д.м.н., профессор, зав. кафедрой эпидемиологии с курсом гигиены ФПК и ППС
614990, г. Пермь, ул. Петропавловская, 26, ГОУ ВПО ПГМА им. ак. Е.А. Вагнера

Росздрава

Тел.: (342) 218-16-68 (служебн.).

E-mail: epidperm@mail.ru 
ботники болеют более часто, длительно и тяжело [2]. По данным российских исследователей в структуре общей заболеваемости медицинского персонала 1-е место занимают инфекционные заболевания (80,2\%), среди которых $46 \%$ приходится на болезни органов дыхания $[1,6]$. Исследования заболеваемости ОРВИ и пневмониями среди медицинских работников, проводимые в Иркутске, показали, что за 5-10 лет ОРВИ в течение года переболели хотя бы раз 76,1土3,7\%, гриппом - 49,2 44,4\% медицинских работника, перенесли пневмонию - 33,1士4,1\% [4].

В связи с вышеизложенным, медицинские работники могут рассматриваться и как группа риска по развитию пневмококковой инфекции, предупреждение которой чрезвычайно важно. В настоящее время наиболее перспективным средством борьбы с пневмококковой инфекцией является вакцинация.

Целью нашей работы явилась оценка реактогенности, безопасности и иммуногенности вакцины «Пневмо 23» при иммунизации медицинских работников.

\section{Материалы и методы}

Исследования проведены на базе 6 учреждений здравоохранения г. Перми, включая врачей и медицинских сестер стационаров и амбулаторно-поликлинических подразделений, а также сотрудников клинических лабораторий. Оценка реактогенности, безопасности и иммуногенности вакцины «Пневмо 23» проведена в условиях рандомизированного клинического наблюдения. Проспективное наблюдение за медицинскими работниками проводилось в течении 28 дней после введения полисахаридной пневмококковой вакцины. Вакцина вводилась в дозе 0,5 мл внутримышечно в дельтовидную мышцу плеча.

Реактогенность вакцины оценивали по наличию поствакцинальных осложнений и общих и местных посвакцинальных реакций. Общие реакции оценивались по степени повышения температуры и выраженности проявлений интоксикации (кратковременное недомогание, головная боль, нарушение сна, аппетита). К слабой реакции относили субфебрильную температуру до $37,5^{\circ} \mathrm{C}$, при отсутствии симптомов интоксикации; к средней - от 37,6 до $38,5^{\circ} \mathrm{C}$, с умеренной интоксикацией; к сильной - выше $38,6^{\circ} \mathrm{C}$ с выраженными симптомами интоксикации.

Оценка выраженности местных реакций проводилась по величине инфильтрата и степени гиперемии. Слабой реакцией считали гиперемию на участке диаметром до 5 см или инфильтрат на месте инъекции до 2,5 см в диаметре; средней - гиперемию диаметром более 5 см или инфильтрат диаметром от 2,6 до 5 см и сильной - инфильтрат более 5 см, также гиперемию 8 см и более.
Безопасность вакцины оценивалась на основании динамики изменения общеклинических и биохимических исследований крови, общего анализа мочи и определения в сыворотке крови $\operatorname{IgE.}$

Иммуногенность вакцины оценивали путем определения в сыворотке крови до иммунизации и спустя 28 дней после введения вакцины IgG антител к антигенам вакцины "Pneumo-23" методом иммуноферментного анализа на твердофазном носителе. Планшеты разборные для ИФА, производства ВНИИ «Медполимер» (Москва), сорбировали вакциной "Pneumo-23" (Авентис Пастер, Франция). Исследования проводились на базе НИИ вакцин и сывороток им. И.И. Мечникова РАМН.

Статистическую обработку результатов выполняли с использованием методов параметрической статистики. Достоверность различия определяли с помощью критерия Стьюдента при $\mathrm{p}<0,05$.

\section{Результаты и обсуждение}

Наблюдение за привитыми выявило поствакцинальные реакции у $50(33,6 \%)$ медицинских работников. В структуре поствакцинальных реакций преобладали слабые местные реакции (56\%), у 8 (16\%) привитых были выявлены слабые общие и у 14 (28\%) - слабые комбинированные (сочетание слабовыраженных местных и общих реакций). Местные реакции проявлялись болью в месте инъекции (продолжительностью от 1 до 5 дней), развитием гиперемии размером 30-40 мм в месте введения вакцины (продолжительностью 2-4 дня) и появлением уплотнения в месте инъекции диаметром до 30 мм (продолжительностью 1-3 дня). Общие реакции были слабой степени выраженности, в виде субфебрильной температуры, кашля, небольшого покраснения горла, головной боли, незначительной миалгии и слабости продолжительностью 2-5 дней.

Местных и общих реакций средней и тяжелой степени, а также поствакцинальных осложнений в процессе наблюдения выявлено не было, что свидетельствует о хорошей переносимости вакцины.

Анализ результатов гематологического анализа крови в динамике иммунизации не выявил статистически достоверных различий показателей (табл. 1).

Не выявлено отклонений от физиологической нормы и показателей общего анализа мочи.

При оценке результатов биохимического анализа крови в динамике иммунизации также не обнаружено статистически достоверных различий между фоновыми показателями и показателями, свидетельствующими о влиянии вакцины на функциональное состояние органов 
ТАБЛИЦА 1. КЛИНИЧЕСКИЕ ПОКАЗАТЕЛИ ГЕМАТОЛОГИЧЕСКОГО АНАЛИЗА КРОВИ У ПРИВИТЫХ МЕДИЦИНСКИХ РАБОТНИКОВ ДО И ПОСЛЕ ИММУНИЗАЦИИ ВАКЦИНОЙ “ПНЕВМО 23" (M $\pm m)$

\begin{tabular}{|l|c|c|}
\hline \multicolumn{1}{|c|}{ Показатели (норма) } & До вакцинации & На 28 день после вакцинации \\
\hline Гемоглобин (120,0-175 г/л) & $133,9 \pm 2,2$ & $135,7 \pm 1,5$ \\
\hline Эритроциты $\left(3,0-5,6 \times 10^{12} /\right.$ л) & $4,4 \pm 0,1$ & $4,5 \pm 0,1$ \\
\hline Лейкоциты $\left(4,0-5,6 \times 10^{9} /\right.$ л) & $5,8 \pm 0,1$ & $6,0 \pm 0,2$ \\
\hline Палочкоядерные $(0,0-6,0 \%)$ & $2,7 \pm 0,3$ & $2,5 \pm 0,3$ \\
\hline Сегментоядерные (47,0-72,0\%) & $54,5 \pm 1,1$ & $52,8 \pm 0,8$ \\
\hline Эозинофилы (0,0-6,0\%) & $2,5 \pm 0,2$ & $2,7 \pm 0,5$ \\
\hline Лимфоциты (18,0-40,0\%) & $34,8 \pm 1,5$ & $35,8 \pm 1,1$ \\
\hline Моноциты (2,0-11,0\%) & $5,3 \pm 0,2$ & $5,6 \pm 0,2$ \\
\hline СОЭ $(0,0-20,0$ мм/4) & $8,6 \pm 0,5$ & $9,9 \pm 0,6$ \\
\hline
\end{tabular}

ТАБЛИЦА 2. КЛИНИЧЕСКИЕ ПОКАЗАТЕЛИ БИОХИМИЧЕСКОГО АНАЛИЗА КРОВИ У ПРИВИТЫХ МЕДИЦИНСКИХ РАБОТНИКОВ ДО И ПОСЛЕ ИММУНИЗАЦИИ ВАКЦИНОЙ ПНЕВМО 23" (M $\pm \mathrm{m})$

\begin{tabular}{|l|c|c|}
\hline \multicolumn{1}{|c|}{ Показатели (норма) } & До вакцинации & На 28 день после вакцинации \\
\hline АЛТ (до 40,0 Ед/л) & $29,2 \pm 5,2$ & $26,4 \pm 1,4$ \\
\hline АСТ (до 40,0 Ед/л) & $28,4 \pm 2,5$ & $27,8 \pm 1,1$ \\
\hline Билирубин общий (до 20 мкм/л) & $11,5 \pm 0,4$ & $11,2 \pm 0,8$ \\
\hline Креатинин (44,0-100,0 мкм/л) & $74,7 \pm 1,6$ & $73,6 \pm 1,2$ \\
\hline Мочевина (2,2-7,2 ммоль/л) & $5,4 \pm 0,1$ & $5,6 \pm 0,1$ \\
\hline Общий белок (65,0-85,0 г/л) & $71,4 \pm 0,6$ & $70,4 \pm 0,5$ \\
\hline
\end{tabular}

и систем при обследовании добровольцев через 28 дней после вакцинации. Иммунизация медицинских работников вакциной «Пневмо 23» не оказала негативного влияния на пигментный обмен, ферментную активность печени и показатели очищения крови. Все показатели оставались в пределах нормы (табл. 2).

Как известно, латентная сенсибилизация, одно из проявлений которой - повышение сывороточных IgE, может протекать без клинических проявлений аллергических заболеваний. Под воздействием некоторых факторов возможен переход латентной формы сенсибилизации в клинически выраженную. Результаты исследования IgE у обследованных до и после вакцинации показали отсутствие изменений концентраций $\operatorname{IgE}(\mathrm{p}>0,05)$ в течение всего периода наблюдения, что свидетельствует об отсутствии у вакцины и аллергизирующих свойств.

Оценка содержания антител до иммунизации показала, что лиц, серонегативных к пневмококку, среди медицинских работников не было, все были серопозитивными. Средняя геометрическая титра до прививки составила 65,9 у.е. После прививки концентрация специфических антител возросла в 2,3 раза и составила 152,1 у.е. Следует заметить, что 34 (29,4\%) привитых медицинских работников дали рост средней геометрической титра в 3 и более раза.

Таким образом, вакцина «Пневмо 23» при иммунизации медицинских работников характеризуется высоким профилем безопасности и достаточной иммуногенностью и может быть рекомендована для вакцинации медицинских работников.

\section{Список литературы}

1. Косарев В.В. Профессиональные заболевания медицинских работников: Монография. - Самара, 1998. - 200 с.

2. Низамов И.Г., Прокопьев В.П. О состоянии здоровья врачей // Советское здравоохранение. 1991. - № 12. - С. 23-26.

3. Пневмококковая инфекция и ее профилактика: пособие для практикующих врачей / Под ред. С.М. Харит. - СПб.: НИИДИ, 2009. - 48 с.

4. Прокопчук Т.С. Эпидемиологический мониторинг инфекционных заболеваний органов дыхания и нервной системы не установленной этиологии. - Автореф. дис. ... канд. мед. наук. - Иркутск, 2007. - 22 с.

5. Чучалин А.Г., СинопальниковхА.И., Страчунский Л.С., Козлов Р.С., Рачина С.А., Яковлев С.В. 
Внебольничные пневмонии у взрослых: практические рекомендации по диагностике, лечению и профилактике // Клин. микробиол. и антимикроб. химиотер. - 2006. - Т. 8, № 1. C. 54-86.

6. Щербо А.П. Больничная гигиена. Руководство для врачей. - СПб.: СПбМАПО, 2000. - 489 с.

7. Granton J.T., Grossman R.F. Community-acquired pneumonia in the elderly patient. Clinical features, epidemiology and treatment // Clin. Chest Med. 1993. - Vol. 14. - P. 537-553.
8. Mandell L.A., Bartlett J.G., Dowell S.F., File T.M. Jr, Musher D.M., Whitney C. Update of practice guidelines for the management of community-acquired pneumonia in immunocompetent adults // Clin. Infect. Dis. - 2003. - Vol. 37, Iss. 11. - P. 1405-1433.

9. Melander E, Mölstad S, Persson K, Hansson HB, Söderström M, Ekdahl K. Previous antibiotic consumption and other risk factors for carriage of penicillin-resistant Streptococcus pneumoniae in children // Eur. J. Clin. Microbiol. Infect. Dis. 1998. - Vol. 17. - P. 834-883. 